\title{
INTERAÇÃO DO INVENTOR INDEPENDENTE COM A UNIVERSIDADE FEDERAL DE MINAS GERAIS: ANÁLISE DA ADOÇÃO DE TECNOLOGIAS
}

\section{INDEPENDENT INVENTOR OF INTERACTION WITH THE FEDERAL UNIVERSITY OF MINAS GERAIS: ANALYSIS OF TECHNOLOGY ADOPTION}

\author{
Bruno de Souza Leite Thiebaut ${ }^{1}$, Luz Elena Jaimes Rios ${ }^{2}$, \\ Vasco Ariston de Carvalho Azevedo ${ }^{3}$
}

RESUMO

A interação entre o inventor independente com as universidades tem o potencial de facilitar que as ideias geradas por aqueles consigam ser aplicadas no setor empresarial, gerando melhorias em processos, produtos e serviços. Com o objetivo de converter o conhecimento em inovação, as universidades brasileiras podem usar a estratégia de adotar as invenções de inventores, melhorando-as ou não, para inserir suas tecnologias no mercado, através de licenciamentos. No intuito de avaliar o processo adoção de invenções e da de transferência de tecnologia de inventores independentes na Universidade Federal de Minas Gerais (UFMG), o presente trabalho apresenta a análise do desempenho da instituição nesta relação particular através do Núcleo de Inovação Tecnológica (NIT), denominado Coordenadoria de Transferência e Inovação Tecnológica (CTIT). Como resultado final, concluiu-se que os inventores independentes pouco exploram essa relação que poderia tornar mais fácil a conversão do seu potencial inventivo em benefícios socioeconômicos e que existem oportunidades de melhoria no processo de transferência de tecnologias.

Palavras-chave: Inventor independente. Universidades. Inovação. Transferência. Tecnologia. UFMG.

\footnotetext{
1 Aluno do Mestrado Profissional em Inovação Tecnológica e Propriedade Intelectual da Universidade Federal de Minas Gerais (UFMG), orientado pelo Prof. Vasco Azevedo.

2 Aluna do Mestrado Profissional em Inovação Tecnológica e Propriedade Intelectual da Universidade Federal de Minas Gerais (UFMG), orientada pelo Prof. Vasco Azevedo.

${ }^{3}$ Professor Titular e pesquisador 1A do CNPq, coordenador do Programa de Pós-Graduação em Bioinformática da UFMG desde 2011 e presidente da Regional Mineira da Sociedade Brasileira de Genética desde setembro de 2014.
} 


\begin{abstract}
The interaction between the independent inventor with universities has the potential to facilitate that ideas generated by those able to be applied in the business sector, generating improvements in processes, products and services. In order to turn knowledge into innovation, Brazilian universities can use the strategy to take the inventions of inventors, improving them or not, to place their technologies on the market, by means of licensing. In order to evaluate the process adoption of inventions and of independent inventors technology transfer at the Federal University of Minas Gerais (UFMG), this paper presents an analysis of the institution's performance in this particular relationship through the Technology Innovation Center (NIT) called Coordination of Technological Transfer and Innovation (CTIT). As a final result, it is concluded that the independent bit inventors exploit this relationship could make it easier to convert the potential socioeconomic benefits and inventive in that there are opportunities for improvement in technologies transfer process.
\end{abstract}

Keywords: Independent Inventor. Universities. Innovation. Transfer. Technology. UFMG.

\title{
1. Introdução
}

Um inventor independente, também conhecido como inventor individual ou inventor de garagem, é uma pessoa física que cria uma invenção geralmente por seus próprios meios, isto é, sem qualquer apoio financeiro de qualquer organização, seja governamental ou privada. A sua principal motivação é a de que possa vir a ganhar dinheiro com sua ideia, mas como ideia não tem nenhum valor no campo da propriedade intelectual a não ser que ela se materialize, é necessário transformá-la em uma inovação.

Dentro desse contexto, a adoção de invenções pelas universidades e a cooperação tecnológica inventor independente-universidade pode ser vista como promissora, já que possibilita que a universidade colabore com o conhecimento acadêmico auxiliando o inventor independente, geralmente com poucos recursos, em converter conhecimento em invenção e posteriormente em inovação, contribuindo para o desenvolvimento do país.

Neste contexto da interação entre o inventor independente e a universidade torna-se relevante conhecer o processo de adoção de invenções de inventores independentes pela Universidade Federal de Minas Gerais (UFMG) e os resultados porventura obtidos com o licenciamento das tecnologias. 


\section{Metodologia}

Neste trabalho, a metodologia utilizada foi a de estudo de caso. De acordo com Yin (2001), é um método abrangente e empírico envolvendo etapas como planejamento, coleta e análise dos dados, podendo incluir o estudo de um único caso ou de vários e abordagens qualitativas e quantitativas de pesquisa.

Para Gil (1995), quatro fases são essenciais para o estudo de caso. A primeira etapa envolveu a consulta a literatura que compreendesse temas referentes aos inventores independentes e à universidade. Além de livros, diferentes repositórios de artigos em meios eletrônicos também foram consultados, que ajudaram a fornecer a fundamentação teórica e ressaltar a argumentação do estudo desenvolvido.

A segunda etapa compreendeu a delimitação do estudo de caso, especificamente a interação inventor independente-universidade e os resultados dessa cooperação. A pouca literatura sobre o tema motivou a escolha deste assunto.

$\mathrm{Na}$ terceira etapa procurou-se colher informações sobre a proteção e o licenciamento das tecnologias na UFMG. Através de documentação disponível consultada na Coordenadoria de Transferência e Inovação Tecnológica (CTIT) da UFMG foi possível obter uma amostra sobre o assunto abordado neste trabalho.

A seguir, na quarta etapa, os dados colhidos foram analisados em conjunto com a literatura utilizada. A seleção dos dados considerou os objetivos deste trabalho com o propósito de determinar quais dados seriam úteis e quais não.

Por fim, chegou-se a etapa das conclusões finais, onde os dados colhidos foram consolidados e validados. Foram propostas, também, algumas indicações para estudos futuros derivados deste trabalho.

\section{Revisão Bibliográfica}

O levantamento bibliográfico realizado visa contextualizar os inventores independentes bem como as universidades nacionais e a importância do relacionamento destes dois integrantes do ambiente nacional de inovação no desenvolvimento de inovações no país. O referencial teórico servirá, também, como base para propor melhorias no estudo de caso apresentado. 


\subsection{O inventor independente no Brasil}

Para qualquer país, produzir ciência e conseguir convertê-la em inovação é um desafio. Os países líderes em tecnologia contam com um ambiente favorável à inovação, através de estímulos tanto das empresas quanto governamentais.

Até alguns anos atrás, não havia no Brasil uma preocupação com a inovação tecnológica, pois o mercado nacional era bem mais fechado do que é hoje e não havia produtos concorrentes estrangeiros. Com o início da liberalização de importações no mercado brasileiro, no início dos anos 1990, que teve a intenção de modernizar o nosso parque tecnológico-industrial, o tema inovação foi colocado em pauta.

Como as inovações se tornaram cada vez mais necessárias, várias peças da complicada engrenagem da inovação nacional começaram a se movimentar, incluindo ai os inventores independentes. Tido como um indivíduo que utiliza de seu período de descanso depois do trabalho ou de seus finais de semana, dedicando seu tempo livre para chegar a uma descoberta surpreendente visando beneficiar a si mesmo e também a sociedade. Não estão ligados a nenhuma empresa ou governo e não recebem nenhum apoio financeiro destes.

No âmbito nacional, grandes nomes que criaram tecnologias e inovações nacionais conseguiram provocar impacto mundial. Nunca é demais lembrar o Padre Roberto Landell de Moura, associado à invenção da radiotransmissão, de Padre Francisco João de Azevedo, relacionado aos primórdios da máquina de escrever, o Padre Bartolomeu Lourenço de Gusmão, com o balão estático, os engenheiros José Braz Araripe e Fernando Lemos ${ }^{4}$, criadores do câmbio automático de veículos, Nélio Nicolai, criador do identificador de chamadas, popularmente conhecido como BINA, sem deixar de mencionar Santos Dumont, com sua máquina de voo autopropelido.

Conforme a Lei $\mathrm{n}^{\mathrm{o}} 10.973 / 2004^{5}$, artigo $2^{\mathrm{o}}$, inciso IX, o inventor independente é a pessoa física que não ocupa nenhum cargo efetivo, cargo militar ou emprego público, que seja inventor, obtentor ou autor de criação.

Contudo, analisando o artigo 90 da Lei $n^{\circ} 9.279 / 96^{6}$, se o empregado de empresa ou instituição pública desenvolveu a invenção ou o modelo de utilidade desvinculado do contrato

\footnotetext{
4 Eles só não inventam lucros. Revista Istoé Dinheiro. Disponível em: http://www.istoedinheiro.com.br/noticias/negocios/20100806/eles-nao-inventam-lucros/42056.shtml. Acesso em 01.09.2015.

${ }^{5}$ Lei $\mathrm{n}^{\circ} 10.973$, de 2 de dezembro de 2004. Dispõe sobre incentivos à inovação e à pesquisa científica e tecnológica no ambiente produtivo e dá outras providências. Disponível em: http://www.planalto.gov.br/ccivil_03/_ato2004-2006/2004/lei/110.973.htm. Acesso em 01.09.2015.
} 
de trabalho (fora do horário e ambiente de trabalho) e não decorrente da utilização de recursos, meios, dados, materiais, instalações ou equipamentos do empregador, a invenção pertencerá exclusivamente ao empregado, deste modo equiparando-se ao inventor independente, já que desenvolveu o invento pelos seus próprios meios.

De acordo com Barbieri ${ }^{7}$, o inventor independente continua sendo muito pouco estudado em nosso país, já que ao longo do tempo tornou-se superada sua forma de trabalho, tendo em vista que o seu espaço foi sendo tomado pelas unidades de pesquisa e desenvolvimento (P\&D) das empresas.

Por outro lado, o Relatório Inventiva ${ }^{8}$, elaborado pela Associação Brasileira dos Inventores e da Propriedade Industrial - ABRIPI em conjunto com o antigo Ministério da Indústria, do Comércio e do Turismo - MICT, a Federação e Centro das Indústrias do Estado de São Paulo - FIESP e o Serviço Brasileiro de Apoio às Micro e Pequenas Empresas - SEBRAE, ressalta que as invenções e inovações desenvolvidas por nacionais de um país são de extrema importância e que o talento inventivo precisa ser estimulado. $\mathrm{Na}$ maioria dos países, as autoridades governamentais demonstram uma crescente consciência da importância em promover internamente a inventividade e a inovação no processo de desenvolvimento tecnológico.

Coadunando com essa afirmação, a Lei de Inovação foi criada para estabelecer incentivos à inovação e à pesquisa científica e tecnológica no Brasil, se incumbindo na promoção de estímulos ao inventor independente, dedicando a estes um capítulo inteiro para impulsionar suas atividades e prevendo que as Universidades, por meio dos Núcleos de Inovação Tecnológica (NIT), tenham a liberdade de adotar as criações dos de inventores independentes que comprovem o depósito de patentes dos seus inventos.

\footnotetext{
${ }^{6}$ Lei $\mathrm{n}^{\circ}$ 9.279, de 14 de maio de 1996. Regula direitos e obrigações relativos à propriedade industrial. Disponível em: http://www.planalto.gov.br/ccivil_03/Leis/L9279.htm. Acesso em 01.09.2015.

${ }^{7}$ BARBIERI, José Carlos. O inventor independente e o empreendedor no Brasil. Fundação Getúlio Vargas. EAESP - Escola de Administração de Empresas de São Paulo. 2005. Disponível em: < http://bibliotecadigital.fgv.br/dspace/handle/10438/3167>. Acesso em: 10 de julho de 2015 .

${ }^{8}$ Associação Brasileira dos Inventores e da Propriedade Industrial - ABRIPI. Estudo da Viabilidade Técnica e Econômica da Inventiva Nacional. Disponível em: http://www.abripi.org.br/wpcontent/uploads/2013/12/Inventiva.pdf. Acesso em: 10 de julho de 2015.
} 


\subsection{As Universidades Federais brasileiras}

Com a criação das primeiras universidades federais, no início dos anos 1900, inicia-se no Brasil o processo de melhoria das capacidades técnicas e científicas, visando o desenvolvimento da educação e da pesquisa no meio acadêmico.

Fávero 9 explica que a Lei Rivadávia Corrêa, implementada em 5 de abril de 1911 pelo decreto $\mathrm{n}^{\circ}$ 8.659, dava liberdade de criação de universidades para os Estados e iniciativa privada e retirava da esfera federal o monopólio do ensino superior no Brasil, e neste contexto foram criadas, em 1909, a Universidade de Manaus, em 1911 a Universidade de São Paulo e, em 1912, a Universidade do Paraná como instituições livres. Ainda, em 7 de setembro de 1920, é oficialmente criada a Universidade do Rio de Janeiro, pelo Decreto $n^{\circ} 14.343$, sendo a primeira instituição universitária legalmente instituída pelo Governo Federal.

Com a Reforma Universitária de 1968 instituída pela Lei $\mathrm{n}^{\circ} 5.540 / 68^{10}$, estabeleceu-se as bases para a expansão e a modernização do ensino superior no Brasil, além da criação do sistema de pós-graduação, o que ajudou no aumento da produção científica brasileira ao longo do período.

Atualmente, considerando o papel da universidade como instituição cuja missão é gerar e transmitir conhecimento, na criação de invenções que podem se transformar em inovações que venham beneficiar a sociedade, no caso específico de propriedade intelectual gerada, observa-se que as universidades públicas brasileiras geraram mais depósitos de patentes e tiveram mais concessões patentárias do que as empresas brasileiras ${ }^{11}$. Esse modelo pode ser considerado inadequado para alguns, mas segundo Amadei e Torkomian ${ }^{12}$, após a Segunda Guerra Mundial, o governo dos Estados Unidos fortaleceu a pesquisa universitária e procurou formas de diminuir a distância entre a universidade e a indústria com o intuito de recuperar sua economia no pós-guerra. Como se observa, atualmente o país norte-americano é um dos

\footnotetext{
${ }^{9}$ FAVERO, Maria de Lourdes de Albuquerque. A universidade no Brasil: das origens à Reforma Universitária de 1968. Educ. rev., Curitiba, n. 28, p. 17-36, dez. $2006 . \quad$ Disponível em $<$ http://www.scielo.br/scielo.php?script=sci_arttext\&pid=S0104-40602006000200003\&lng=pt\&nrm=iso $>$. Acessos em 17 setembro de 2015.

${ }^{10}$ LEI N ${ }^{\circ}$ 5.540, DE 28 DE NOVEMBRO DE 1968. Fixa normas de organização e funcionamento do ensino superior e sua articulação com a escola média, e dá outras providências. Disponível em: <http://www.planalto.gov.br/CCivil_03/Leis/L5540.htm>. Acesso em 29 de agosto de 2015.

${ }^{11}$ DAGNINO, Renato; SILVA, Rogério Bezerra da. As patentes das universidades públicas. Revista Economia \& Tecnologia, [S.1.], v. 5, n. 3, mai. 2012. ISSN 2238-1988. Disponível em: $<$ http://ojs.c3sl.ufpr.br/ojs/index.php/ret/article/view/27147/18073>. Acesso em 01 de setembro de 2015.

${ }^{12}$ AMADEI, José Roberto Plácido; TORKOMIAN, Ana Lúcia Vitale. As patentes nas universidades: análise dos depósitos das universidades públicas paulistas (1995-2006). Ci. Inf., Brasília, v. 38, n. 2, p. 9-18, agosto de 2009 Disponível em: $<\mathrm{http}: / / \mathrm{www}$. scielo.br/scielo.php?script=sci_arttext\&pid=S0100$19652009000200001 \& \operatorname{lng}=$ en\&nrm=iso $>$. Acesso em 01 de setembro de 2015.
} 
maiores depositantes de pedidos de patentes no mundo, segundo dados recentes da Organização Mundial da Propriedade Intelectual (OMPI) ${ }^{13}$.

De acordo com Rapini ${ }^{14}$, a universidade deve desempenhar um novo papel como ator no âmbito da inovação por conta da importância cada vez maior da informação e do conhecimento no processo produtivo, levando a evolução de alguns setores industriais. Essa afirmativa credencia as universidades federais brasileiras como um instrumento necessário para elevar o patamar do desenvolvimento nacional, dentro de um contexto onde as empresas não se mostram como impulsionadoras da inovação no Brasil.

Em matéria de produção científica, pela quantidade de trabalhos acadêmicos que são publicados em revistas especializadas, o Brasil deu um salto em quantidade de publicações segundo o Institute for Scientific Information (ISI), uma das principais bases de dados que qualificam revistas científicas no mundo. Passou de cerca de 20 mil em 2007 para 30.415 em $2008^{15}$

Com a promulgação da Lei $n^{0} 10.973 / 2004$, a chamada Lei de Inovação, deu oportunidade para que as Instituições Federais de Ensino Superior (IFES) assumissem função relevante em aprimorar o parque tecnológico e industrial brasileiro. A lei viabiliza a melhoria nas parcerias público-privadas, por meio de regras mais claras, permite a prestação de serviços, promove incentivos aos pesquisadores e busca fomentar o desenvolvimento nacional, através do aumento de competitividade das empresas.

\section{Estudo de caso}

O estudo de caso foi realizado consultando dados da Coordenadoria de Transferência e Inovação Tecnológica (CTIT) da Universidade Federal de Minas Gerais (UFMG), um dos principais Núcleos de Inovação Tecnológicos nacionais. As informações apresentadas servem como base para se ponderar sobre a importância do inventor independente e a adoção de suas invenções em universidades brasileiras, o que pode vir a contribuir para a inovação e a competitividade brasileira.

\footnotetext{
13 World Intellectual Property Indicators. Disponível em: $<$ http://www.wipo.int/edocs/pubdocs/en/wipo_pub_941_2014.pdf >. Acesso em 02 de Setembro de 2015.

${ }^{14}$ RAPINI, M.S. Interação universidade-empresa no Brasil: Evidências do Diretório dos Grupos de Pesquisa do CNPq. Estudos Econômicos. Instituto de Pesquisas Econômicas. , v.37, p.211 - 233, 2007.

15 Revista Em Discussão!.

Disponível

em: http://www.senado.gov.br/NOTICIAS/JORNAL/EMDISCUSSAO/upload/201203\%20$\% 20$ setembro/pdf/em\%20discuss\%C3\%A3o!_setembro_2012_internet.pdf. Acesso em 28 de agosto de 2015.
} 


\subsection{A Universidade Federal de Minas Gerais (UFMG)}

Tendo como base informações e dados obtidos no site da própria instituição ${ }^{16}$, a UFMG foi fundada em 7 de setembro de 1927, com o nome de Universidade de Minas Gerais (UMG), como instituição privada que recebia subsídios do governo do Estado, e permaneceu nesta condição até o ano de 1949, quando passou para a esfera federal. A universidade continuou com o nome antigo até 1965, quando finalmente recebeu a designação atual de Universidade Federal de Minas Gerais (UFMG).

A UFMG está entre as que mais recebem verbas estatais, segundo dados do Governo Federal $^{17}$.

Em termos numéricos ${ }^{18}$, a estrutura da universidade compreende 04 campi universitários e 20 unidades acadêmicas. Em termos de docência, a universidade dispõe de um total de 2.818 professores, dos quais 226 possuem o título de mestres e 2.543 obtiveram o título de doutor.

Em quantidade de alunos, a UFMG tem atualmente 48.949 discentes, sendo que 33.242 são alunos de graduação, distribuídos em cerca de 75 cursos presenciais, e 14.013 estão na pósgraduação.

Na produção científica, a universidade publicou 4.302 artigos em periódicos no ano de 2014 . Com 63 cursos de doutorado e 77 de mestrado, além 68 cursos de especialização lato sensu, $74,3 \%$ de seus cursos tiveram conceito entre 5 e 7 em 2013 pela Comissão de Aperfeiçoamento de Pessoal do Nível Superior - CAPES, que é o órgão responsável pelo reconhecimento e a avaliação de cursos de pós-graduação stricto-sensu (mestrado profissional, mestrado acadêmico e doutorado) em âmbito nacional.

Com 2.500 pesquisadores, que até setembro de 2015 contribuíram para que a UFMG depositasse 688 pedidos de patentes junto ao Instituto Nacional de Propriedade Industrial (INPI), além de 296 patentes depositadas em nível internacional. Foram realizados 78 contratos de licenciamento de tecnologias patenteadas, colaborando para que a universidade receba royalties que posteriormente são investidos em fomentos à pesquisa e inovação, em cumprimento ao disposto na Lei de Inovação Tecnológica (Lei no 10.973/04) e n Resolução

\footnotetext{
16 Universidade Federal de Minas Gerais. História da UFMG. Disponível em: $<$ https://www.ufmg.br/conheca/hi_index.shtml>. Acesso em 01 de setembro de 2015.

17 Portal da Transparência

http://www.portaldatransparencia.gov.br/PortalComprasDiretasOEOrgaoSubordinado.asp?Ano=2013\&CodigoO $\mathrm{S}=26000 \&$ Pagina $=10$

18 Universidade Federal de Minas Gerais. UFMG em números. Disponível em: $<$ https://www.ufmg.br/conheca/nu_index.shtml>. Acesso em 01 de setembro de 2015.
} 
08/98, do Conselho Universitário, que determina que os recursos obtidos pela UFMG através de royalties por transferências de tecnologias deverá ser repartida entre os inventores, as unidades acadêmicas onde estiverem vinculados e a Administração Central.

Esses números têm contribuído para que a UFMG seja uma das universidades mais inovadoras no país, sendo muito procurada por candidatos para ingressar em seus cursos. Está bem avaliada em vários indicadores nacionais e internacionais.

\subsection{O processo de adoção de inventos de inventores independentes na UFMG}

O setor consultado para elaboração deste trabalho foi a Coordenadoria de Transferência e Inovação Tecnológica (CTIT) da UFMG, responsável pela gestão do conhecimento científico e tecnológico da Universidade, ligado à Pró-reitora de Pesquisa.

De acordo com a Lei de Inovação (Lei ${ }^{\circ}$ 10.973/2004), em seu artigo 22, o inventor independente poderá solicitar a adoção de seu invento, desde que comprovado o depósito de pedido de patente por ele para que seu invento participe de projeto voltado a sua avaliação para futuro desenvolvimento, incubação, utilização e industrialização pelo setor produtivo, desde que seja do interesse da Instituição Científica e Tecnológica (ICT). Caso a invenção adotada pela ICT logre êxito na exploração comercial, o inventor independente deverá compartilhar os ganhos econômicos com a instituição.

Barbosa $^{19}$, todavia, traz uma observação interessante ao considerar que tal exigência de depósito de pedido de patente para se pleitear exame pela ICT para ser adotado é, no mínimo, inesperado. Poderíamos considerar que a menção ao depósito de patente seria um mero documento, articulado e formal, com critérios similares ao depósito de patente da invenção a ser avaliada e possivelmente adotada pela ICT. Interessante observar que o artigo em comento em momento algum exige que o depósito de pedido de patente esteja registrado junto ao INPI. Assim sendo, qualquer pretensão que esteja formalmente bem documentada, condizente com o que estabelece o INPI, deverá possibilitar ao exame de adoção. Para a ICT, é até mais interessante que o depósito de pedido de patente não esteja formalizado junto ao INPI, pois a equipe técnica porventura atuando em seu NIT conseguirá detectar eventuais falhas e incongruências no documento e assim, lograr que o depósito seja bem-sucedido.

\footnotetext{
${ }^{19}$ BARBOSA, Denis Borges. Direito da Inovação. Comentários à Lei no 10.973/2004, Lei Federal de Inovação. Editora Lumen Juris. Rio de Janeiro. 2006, p.246.
} 
Em harmonia com a Lei de Inovação, mas também com o argumento acima, a CTIT analisa tecnologias de inventores independentes com depósitos de pedido de patente correspondentes junto ao INPI e também quando o mesmo possui um documento descrevendo a invenção. Nesse caso, quem fará a análise de patenteabilidade é um setor específico do órgão, o Setor de Propriedade Intelectual. Essa análise de patenteabilidade irá avaliar potenciais problemas no documento referente à invenção e também irá examinar o potencial mercadológico do invento.

Caso a tecnologia seja patenteável após a análise do Setor de Propriedade Intelectual da CTIT, essa demanda é repassada para o Setor de Transferência de Tecnologia, que fará nova avaliação sobre o interesse em adotar a tecnologia.

No caso de a tecnologia não ser patenteável, o Setor de Propriedade Intelectual emitirá um relatório dando ciência ao inventor independente sobre a impossibilidade de proteção por patente, que virá acompanhada de um documento chamado de "Decisão de Demanda de Inventor Independente" de que não houve interesse da UFMG em adotar o pedido porque o mesmo carece de patenteabilidade. Será, ainda, agendada uma para apresentação dos documentos pessoalmente, onde serão explicados os motivos de não-adoção da tecnologia.

\subsection{Números obtidos}

Foram pesquisados 300 instrumentos jurídicos celebrados entre a UFMG com outros parceiros desde a sua criação até outubro de 2015. Neste universo, foram identificados 2 convênios de desenvolvimento de pesquisa, 3 contratos de cotitularidade, 1 termo de autorização de teste e 3 contratos de licenciamento de tecnologia, totalizando 09 dispositivos com inventores independentes, ou seja, apenas 3\% do total. Destes, os que mais interessavam eram os 2 convênios de desenvolvimento de pesquisa e os 3 contratos de licenciamento de tecnologia celebrados.

Conforme instrui Di Pietro, "define-se o convênio como forma de ajuste entre o Poder Público e entidades públicas ou privadas para a realização de objetivos de interesse comum, mediante mútua colaboração" ${ }^{20}$. Os convênios visam desenvolver uma tecnologia na Universidade, contando com a colaboração dos pesquisadores para obter melhorias na tecnologia adotada pela instituição. Pode haver ou não investimento financeiro da parte do inventor independente, como contrapartida financeira, fato que ocorreu em um dos convênios celebrados.

\footnotetext{
${ }^{20}$ Di Pietro, Maria Sylvia Zanella. Direito administrativo. 17ª ed. São Paulo: Atlas, 2004. Pág. 292. 
Deve-se observar a possibilidade de que a melhoria gere um certificado de adição à tecnologia do inventor independente, e, neste caso, a titularidade será da UFMG e do inventor.

Considerando que a universidade é a instituição que possui o melhor potencial de geração de novas tecnologias bem como de melhorar as já existentes, tendo como dever a transferência desta tecnologia em prol da sociedade ${ }^{21}$, por meio de um produto que englobe benefícios e desenvolvimento social e ainda contemplando que o objetivo final dos inventores independentes e também da Universidade é conseguir que o invento patenteado seja licenciado, para que o inventor obtenha o retorno financeiro do investimento realizado e a Universidade possa receber royalties, nota-se claramente que são poucas tecnologias desenvolvidas pelos inventores independentes que conseguem chegar até a fase de comercialização. Pode ser um indicativo de que muitos inventores independentes desconheçam o tratamento que lhes é dispensado pela Lei $n^{\circ} 10.973 / 2004$ e também de que existe uma dificuldade para se patentear um invento desenvolvido fora dos limites universitários ou de laboratórios de $\mathrm{P} \& \mathrm{D}$, tendo em vista que essas instituições geralmente possuem uma assessoria na área de propriedade intelectual, capazes de elaborar, do início ao fim, todo o pedido de depósito de patente. Nota-se também que o caminho de um invento patenteado até alcançar sucesso comercial não é nada fácil, pois o mercado muitas vezes não acredita em um produto se não estiver apoiado por uma empresa ou marca de renome.

Com efeito, apenas três tecnologias de inventores independentes obtiveram sucesso em serem licenciadas para empresas e apenas uma, efetivamente, foi colocada à disposição da sociedade. Em termos financeiros, do ano de 2004 até dezembro de 2014, a UFMG obteve o montante de $\mathrm{R} \$ 2.838 .836,15$ com o licenciamento de tecnologias. No mesmo período, as empresas licenciantes de tecnologias de inventores independentes pagaram royalties no valor total de R\$13.563,97.

\section{Considerações Finais}

O estudo de caso permitiu identificar os desafios enfrentados pelos inventores independentes ao oferecerem suas tecnologias para serem adotadas pela UFMG. Nota-se que o processo de adoção não possui grandes entraves, tratando-se mais de análises técnicas e comerciais sobre a invenção.

\footnotetext{
${ }^{21}$ COELHO, Juliana Lagoas. Análise da produção intelectual dos pesquisadores-inventores da Universidade Federal do Rio Grande do Sul que possuem patentes. Disponível em:

$<$ http://www.lume.ufrgs.br/bitstream/handle/10183/29759/000591927.pdf?sequence=1 $>$ Acesso em $01 \mathrm{de}$ novembro de 2015.
} 
Observa-se que as universidades brasileiras oferecem espaço para a adoção e consequente desenvolvimento de tecnologias provenientes dos inventores independentes, em obediência à Lei de Inovação. É importante que exista a análise prévia de invenções a serem adotadas pela universidade, capazes de fornecer estratégias tecnológico-comerciais e de avaliação potencial de mercado, para que não sejam integradas tecnologias que, ao final, não venham conseguir nenhum licenciamento.

Entretanto, o baixo impacto na adoção e transferência das tecnologias levadas pelos inventores independentes mostra que existe um desconhecimento nesse formato de geração de tecnologia e inovação. O retorno obtido pelos inventores e também pela UFMG com a adoção e licenciamento de tecnologias é muito baixo, levando-se em conta os investimentos feitos pelas partes, mas existe potencial para alcançar valores mais elevados, no momento em que se criar uma maior percepção na comunidade de inventores independentes de que existe uma relação da importância da proteção de invenções e da criação de mais tecnologias que gerem inovações para o mercado.

Assim, deve-se buscar uma maior divulgação para os inventores independentes desta modalidade de estímulo à inovação através das universidades, inserindo também o governo nesse processo, promovendo maior interação entre as partes. De sua parte, os inventores independentes deverão ter noções de empreendedorismo e mercado, para que não caiam na tentação de reinventar a roda.

Algumas perguntas relacionadas a esse assunto podem auxiliar em futuros trabalhos: é interessante para as ICT's adotarem tecnologias dos inventores independentes? Como ajudar o inventor a ter o discernimento sobre a invenção ter uma aplicação industrial e também ser aquilo que o mercado deseja? Como facilitar a criação de um protótipo e/ou uma cabeça-desérie? O inventor independente tem a noção de que tecnologia e inovação hoje em dia é, basicamente, um negócio?

Diante das perguntas apresentadas, este trabalho possui, como produto final, uma ampla visão sobre o processo de adoção de tecnologias de inventores independentes pelas universidades brasileiras, e abre a possibilidade de novas linhas de trabalhos acadêmicos sobre o assunto.

\section{Referências}

AMADEI, José Roberto Plácido; TORKOMIAN, Ana Lúcia Vitale. As patentes nas universidades: análise dos depósitos das universidades públicas paulistas (1995-2006).
Ci. Inf.,
Brasília ,
v. 38 ,
. 2, p. 9-18, agosto de 2009 .
Disponível em: 
$<$ http://www.scielo.br/scielo.php?script=sci_arttext\&pid=S0100-

$19652009000200001 \& \operatorname{lng}=$ en\&nrm=iso $>$. Acesso em 01 de setembro de 2015.

Associação Brasileira dos Inventores e da Propriedade Industrial - ABRIPI. Estudo da Viabilidade Técnica e Econômica da Inventiva Nacional. Disponível em: http://www.abripi.org.br/wp-content/uploads/2013/12/Inventiva.pdf. Acesso em: 10 de julho de 2015 .

BARBIERI, José Carlos. O inventor independente e o empreendedor no Brasil. Fundação Getúlio Vargas. EAESP - Escola de Administração de Empresas de São Paulo. 2005. Disponível em: < http://bibliotecadigital.fgv.br/dspace/handle/10438/3167>. Acesso em: 10 de julho de 2015.

BARBOSA, Denis Borges. Direito da Inovação. Comentários à Lei $n^{0}$ 10.973/2004, Lei Federal de Inovação. Editora Lúmen Juris. Rio de Janeiro. 2006

BRASIL. LEI N ${ }^{0}$ 5.540, DE 28 DE NOVEMBRO DE 1968. Fixa normas de organização e funcionamento do ensino superior e sua articulação com a escola média, e dá outras providências. Disponível em <http://www.planalto.gov.br/CCivil_03/Leis/L5540.htm>. Acesso em 29 de agosto de 2015.

BRASIL. Lei $\mathrm{n}^{0}$ 9.279, de 14 de maio de 1996. Regula direitos e obrigações relativos à propriedade industrial. Disponível em: http://www.planalto.gov.br/ccivil_03/Leis/L9279.htm. Acesso em 01.09.2015.

BRASIL. Lei $\mathrm{n}^{\circ} 10.973$, de 2 de dezembro de 2004. Dispõe sobre incentivos à inovação e à pesquisa científica e tecnológica no ambiente produtivo e dá outras providências. Disponível em: <http://www.planalto.gov.br/ccivil_03/_ato2004-2006/2004/lei/110.973.htm>. Acesso em 01.09.2015.

COELHO, Juliana Lagoas. Análise da produção intelectual dos pesquisadores-inventores da Universidade Federal do Rio Grande do Sul que possuem patentes. Disponível em: < http://www.lume.ufrgs.br/bitstream/handle/10183/29759/000591927.pdf?sequence=1> Acesso em 01 de novembro de 2015.

DAGNINO, Renato; SILVA, Rogério Bezerra da. As patentes das universidades públicas. Revista Economia \& Tecnologia, [S.1.], v. 5, n. 3, mai. 2012. ISSN 2238-1988. Disponível em: <http://ojs.c3sl.ufpr.br/ojs/index.php/ret/article/view/27147/18073>. Acesso em 01 de setembro de 2015.

DI PIETRO, Maria Sylvia Zanella. Direito administrativo. 17ª ed. São Paulo: Atlas, 2004.

EM DISCUSSÃO!. Revista de audiências públicas do Senado Federal. Disponível em: < http://www.senado.gov.br/NOTICIAS/JORNAL/EMDISCUSSAO/upload/201203\%20$\% 20$ setembro/pdf/em\%20discuss\%C3\%A3o!_setembro_2012_internet.pdf $>$. Acesso em 28 de agosto de 2015.

FAVA-DE-MORAES, FLAVIO. Universidade, inovação e impacto socioeconômico. São Paulo Perspec., São Paulo, v.14, n.3, p.8-11, Julho de 2000. Disponível em 
$<$ http://www.scielo.br/scielo.php?script=sci_arttext\&pid=S0102-

$88392000000300003 \& \operatorname{lng}=\mathrm{en} \& n r m=$ iso $>$. Acesso em 28 de agosto de 2015.

FAVERO, Maria de Lourdes de Albuquerque. A universidade no Brasil: das origens à Reforma Universitária de 1968. Educ. rev., Curitiba, n. 28, p. 17-36, dez. 2006 . Disponível em $\quad<$ http://www.scielo.br/scielo.php?script=sci_arttext\&pid=S0104$40602006000200003 \& \operatorname{lng}=$ pt\&nrm=iso $>$. Acesso em 28 de agosto de 2015.

GIL, Antônio Carlos. Como elaborar projetos e pesquisa. 3a ed. São Paulo: Atlas; 1995.

MARTINS, Carlos Benedito. A reforma universitária de 1968 e a abertura para o ensino superior privado no Brasil. Educ. Soc., Campinas, v. 30, n. 106, p. 15-35, abr. 2009. Disponível em $\quad<$ http://www.scielo.br/scielo.php?script=sci_arttext\&pid=S0101$73302009000100002 \& \operatorname{lng}=$ en\&nrm=iso $>$. Acesso em 01 de setembro de 2015 .

PORTAL DA TRANSPARÊNCIA. Disponível em: $<$ http://www.portaldatransparencia.gov.br/PortalComprasDiretasOEOrgaoSubordinado.asp?A no $=2013 \&$ CodigoOS $=26000 \&$ Pagina $=10>$. Acesso em 01 de setembro de 2015 .

UNIVERSIDADE FEDERAL DE MINAS GERAIS. História da UFMG. Disponível em: $<$ https://www.ufmg.br/conheca/hi_index.shtml>. Acesso em 01 de setembro de 2015.

UNIVERSIDADE FEDERAL DE MINAS GERAIS. UFMG em números. Disponível em: $<$ https://www.ufmg.br/conheca/nu_index.shtml>. Acesso em 01 de setembro de 2015.

YIN, Robert K. Estudo de caso: planejamento e métodos. 2a ed. Porto Alegre: Bookman; 2001.

WIPO - World Intellectual Property Organization. World Intellectual Property Indicators. Disponível em: <http://www.wipo.int/edocs/pubdocs/en/wipo_pub_941_2014.pdf > Acesso em 28 de agosto de 2015.

WIPO - World Intellectual Property Organization. Who Filed The Most PCT Patent Applications in 2013?. Disponível em: $<$ http://www.wipo.int/export/sites/www/ipstats/en/docs/infographics_patents_2013.pdf $>$.

Acesso em 28 de agosto de 2015.

RAPINI, M.S. Interação universidade-empresa no Brasil: Evidências do Diretório dos Grupos de Pesquisa do CNPq. Estudos Econômicos. Instituto de Pesquisas Econômicas. v.37, p.211 - 233, 2007.

Revista Istoé Dinheiro. Eles só não inventam lucros. Disponível em: http://www.istoedinheiro.com.br/noticias/negocios/20100806/eles-nao-inventamlucros/42056.shtml. Acesso em 01.09.2015.

Recebido 13/01/2016

Aprovado 25/01/2016

Publicado 29/02/2016 